13.2

\title{
Автоэмиссия многоострийных катодных матриц на кремнии $p$-типа в сильных импульсных электрических полях
}

\author{
() Р.К. Яфраров \\ Саратовский фрилиал Института радиотехники и электроники им. В.А. Котельникова РАН, Саратов, Россия \\ E-mail: pirpc@yandex.ru
}

Поступило в Редакцию 31 января 2019 г.

В окончательной редакции 31 января 2019 г.

Принято к публикации 5 февраля 2019 г.

\begin{abstract}
Экспериментально исследованы динамические свойства автоэлектронной эмиссии в сильных импульсных электрических полях микросекундной длительности для многоострийных катодных матриц, изготовленных на основе поверхностно модифицированных кристаллов кремния дырочного типа. Показано, что уменьшение порогов начала автоэмиссии с увеличением длительности импульсов увеличивает прозрачность потенциальных барьеров за счет увеличения энергии электронов. Параметры автоэмиссии определяются дипольными моментами поверхностей и встроенными поверхностными потенциалами, которые формируются при плазменном травлении кремния в различных химически активных средах.
\end{abstract}

DOI: 10.21883/PJTF.2019.09.47702.17721

Развитие вакуумной микроэлектроники в настоящее время во многом определяется возможностями увеличения частотного диапазона работы полевых источников электронов, используемых при создании активной элементной базы, и снижением времени готовности, которое характеризуется длительностью выхода параметров автоэмиссии на стационарный режим функционирования. Одним из наиболее привлекательных материалов для полевых источников электронов вакуумной микроэлектроники остается кристаллический кремний $[1,2]$. В первую очередь это обусловлено развитой технологической базой, а также обнаруженными люминесцентными свойствами нанокристаллического кремния, которые позволяют надеяться на создание в будущем сверхбыстродействующих радиационно-стойких кремниевых интегральных схем с оптической связью $[3,4]$.

Целью настоящей работы является исследование эмиссионной способности в сильных импульсных электрических полях наноструктурированных кремниевых катодных матриц, модифицированных с использованием плазмохимической обработки в различных химически активных средах.

Получение поверхностно наноструктурированных кремниевых катодных матриц проводилось в вакуумной установке с использованием СВЧ ионно-плазменного источника, описанного в работе [5]. Мощность СВЧ-излучения и индукция магнитного поля, соответствующая возникновению в зоне газового разряда электронно-циклотронного резонанса, составляли $250 \mathrm{~W}$ и $875 \mathrm{G}$ соответственно. Давление рабочих газов в процессе плазменной обработки было равно 0.1 Ра и обеспечивало выполнение условий электронно-циклотронного резонанса, при котором степень ионизации плазмы составляла $\sim 5 \%$ [5]. В качестве рабочих газов для травления пластин кремния, пассивированных тонкой пленкой естественного окисла, использовались хладон-14 и аргон. Величины ускоряющих напряжений в процессах плазменного травления были фиксированными и составляли $-100 \mathrm{~V}$. Исследовались автоэмиссионные свойства кристаллов кремния КДБ (0.01-0.02) ориентации (100). Процесс их поверхностного наноструктурирования осуществлялся в одном технологическом цикле по методике, изложенной в работах [6,7]. Поверхностная плотность и высота острий наноструктурированных поверхностей кристаллов кремния составляли соответственно $\rho \approx(3-5) \cdot 10^{10} \mathrm{~cm}^{-2}$ и $h \approx 7-10 \mathrm{~nm}$. Исследования автоэмиссионных свойств проводились в условиях высокого вакуума $\left(10^{-5} \mathrm{~Pa}\right)$ на диодной структуре, способной изменять расстояние между электродами с точностью до $1 \mu \mathrm{m}$. Расстояние между анодом и катодной структурой $20 \mu \mathrm{m}$. Диаметр рабочей поверхности анода, изготовленного из углеродного материала МПГ-6, составлял $3 \mathrm{~mm}$. Исследовано влияние длительности импульсов $(10,30,50 \mu \mathrm{s})$ и амплитуды напряжений (от $10 \mathrm{~V}$ до $3.5 \mathrm{kV}$ ) при различных частотах повторения импульсов на порог начала автоэмиссии, автоэмиссионные токи и длительности установления стационарных режимов при импульсном воздействии сильных электрических полей. Пороги начала автоэмиссии определялись по напряженности электрического поля, при которой токи автоэмиссии составляли $5 \mu \mathrm{A}$. Длительность импульсных воздействий составляла 5 и $10 \mathrm{~min}$.

На рис. 1-3 приведены зависимости порогов и токов автоэмиссии от длительности импульсов анодных напряжений, а также амплитуд автоэмиссионных токов от количества импульсов анодных напряжений различной длительности при напряженности поля, превышающей порог автоэмиссии на $10 \mathrm{~V} / \mu \mathrm{m}$, для кристаллов кремния с плазменной обработкой в различных химически активных средах. Из экспериментальных данных следует, что при плазменной обработке в среде аргона с увеличением длительностей импульсов пороги начала авто- 

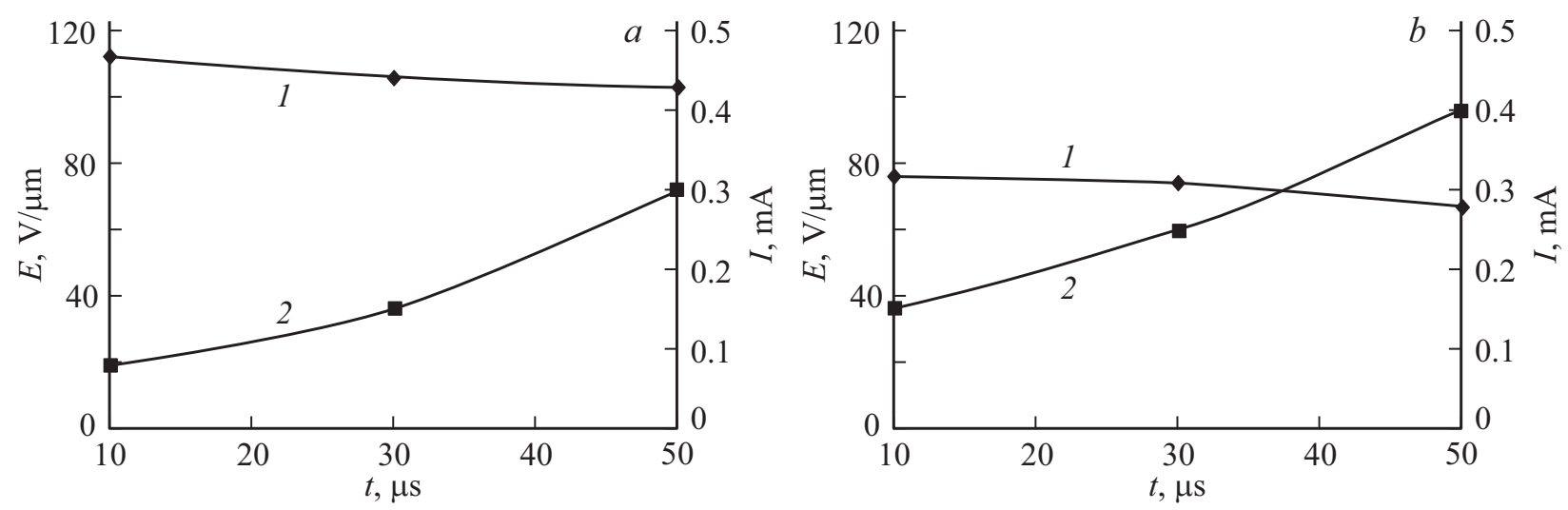

Рис. 1. Зависимости порогов (1) и токов автоэмиссии (2) при напряженности поля, превышающей порог автоэмиссии на $10 \mathrm{~V} / \mu \mathrm{m}$, от длительности импульсов анодных напряжений для кристаллов кремния с плазменной обработкой в различных химически активных средах. $a-\mathrm{Ar}, b-\mathrm{CF}_{4}$.

эмиссии монотонно уменьшаются от 112 до $103 \mathrm{~V} / \mu \mathrm{m}$ с одновременным увеличением автоэмиссионных токов от 0.1 до $0.3 \mathrm{~mA}$ (рис. 1, a). При длительных импульсных воздействиях анодных напряжений амплитуды автоэмиссионных токов практически мгновенно выходят на стационарный уровень для всех длительностей импульсов (рис. 2).

Для кристаллов, обработанных в плазме $\mathrm{CF}_{4}$, характеры изменения порогов начала автоэмисси и автоэмиссионных токов в зависимости от длительностей импульсов такие же, как при обработке в плазме аргона (рис. $1, b)$. Однако при обработке в плазме хладона14 пороги автоэмиссии значительно меньше, а токи выше. При долговременных испытаниях с короткими длительностями импульсов наблюдается небольшое уменьшение огибающих амплитуд анодных импульсов. При длительностях импульсов более $30 \mu \mathrm{s}$ амплитуды автоэмиссионных токов не зависят от длительности испытаний (рис. 3).

Одинаковые тенденции уменьшения порогов начала автоэмиссии и рост автоэмиссионных токов для обоих видов плазменной обработки при увеличении длительности импульсов электрических полей свидетельствуют, согласно представлениям Фаулера и Нордгейма [8], о возрастании прозрачности потенциальных барьеров. Причиной этого является увеличение собственной (кинетической) энергии туннелирующих электронов с ростом длительности импульсов электрических полей. Различие в абсолютных значениях порогов начала автоэмиссии и автоэмиссионных токов может быть объяснено различием встроенных поверхностных потенциалов и дипольных моментов эмитирующих поверхностей, которые формируются при плазменном травлении кристаллов кремния в различных химически активных средах $[7,9]$.

При использовании низкоэнергетической плазмы аргона травление осуществляется по ионно-физическому механизму за счет распыления атомов кремния и частиц его естественного окисла ускоренными ионами. Благода- ря инертности аргона химические связи с поверхностными атомами кремния не образуются. В результате такой обработки поверхность кремния приобретает структуру и плотность оборванных (ненасыщенных) связей, характерных для атомно-чистой поверхности кремния заданной кристаллографической ориентации [10]. Поверхностные атомы кремния, имеющие ненасыщенную химическую связь, действуют как дырочные ловушки, заряжаясь положительно при отдаче электронов в зону проводимости полупроводника и/или при их туннелировании в бомбардирующий ион аргона, когда их электронные волновые функции перекрываются. Это приводит к ухудшению проводимости приповерхностного слоя и образованию в нем трехвалентного кремния с положительным зарядом.

При плазмохимическом травлении кремния в $\mathrm{CF}_{4}$ химически активными частицами являются ионы $\mathrm{C}^{+}, \mathrm{CF}_{n}^{+}$, где $n=1 \ldots 4$, а также радикалы $\mathrm{CF}_{n}$ и нейтральные атомы фтора, которые при хемосорбции образуют адкомплексы $\mathrm{Si}-\mathrm{C}$ и $\mathrm{Si}-\mathrm{F}$ [5]. Хемосорбированные комплексы $\mathrm{SiC}$ и $\mathrm{SiF}$ имеют сильные энергии химической связи (4.55 и $5.6 \mathrm{eV}$ соответственно), которые превышают энергию химических связей атомов кремния $(3.38 \mathrm{eV})$, и пассивируют часть оборванных (ненасыщенных) химических связей поверхностных атомов кремния, уменьшая их поверхностную плотность.

Формирование ненасыщенных электронных связей при плазмохимическом травлении приводит к образованию на поверхности кремния встроенного положительного заряда, поверхностная плотность которого выше в случае использования плазмы аргона. Вследствие этого при обработке в плазме хладона-14 уменьшаются (по сравнению с таковыми при обработке в плазме аргона) величина приповерхностного электрического поля, направленного в объем полупроводника, а также степень обеднения приповерхностной области кремния основными носителями. Это приводит к уменьшению порогов „включения“ проводимости и полевой эмиссии. При одинаковой величине внешнего электрического поля 


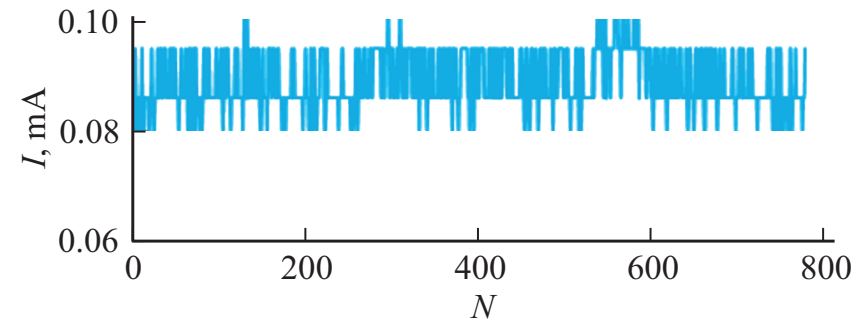

Рис. 2. Зависимость амплитуд анодных токов от количества импульсов с длительностью $10 \mu$ s для кристаллов $p$-типа, обработанных в плазме аргона.

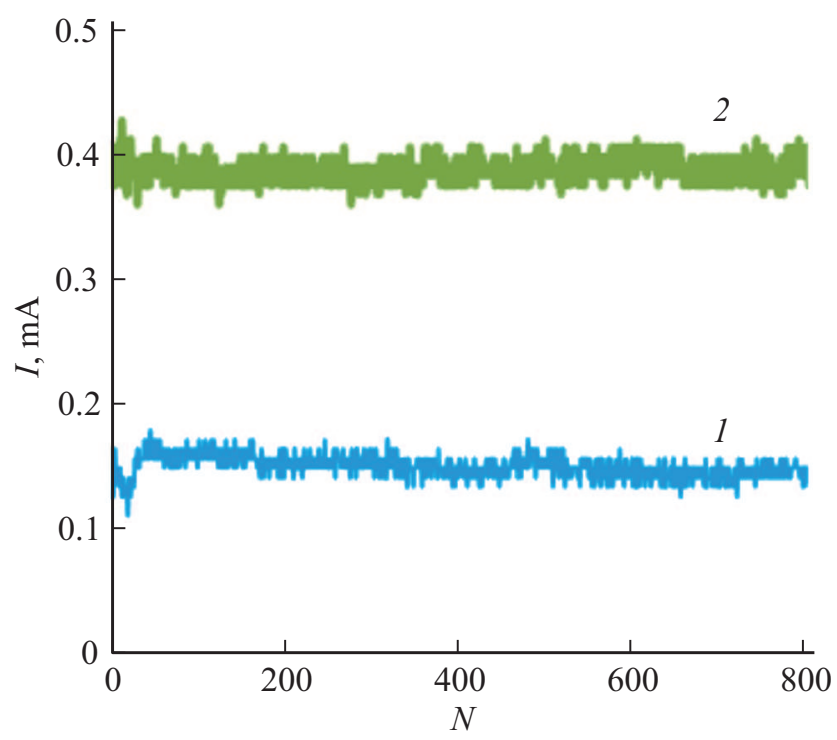

Рис. 3. Зависимости амплитуд автоэмиссионных токов от количества импульсов анодных напряжений длительностью $10(1)$ и $50 \mu \mathrm{s}(2)$ при напряженностях поля, превышающих порог автоэмиссии на $10 \mathrm{~V} / \mu \mathrm{m}$, для кристаллов кремния с плазменной обработкой в среде $\mathrm{CF}_{4}$.

автоэмиссионный ток катодной матрицы, обработанной в плазме хладона-14, увеличивается (рис. 1). Однако это увеличение не является достаточно существенным, как это следовало бы ожидать из снижения порогов начала автоэмиссии и представлений Фаулера и Нордгейма. Причиной этого является высокая электроотрицательность атомов фтора, которые увеличивают дипольный момент эмитирующих центров из-за присутствия на поверхности кремния диполей $\mathrm{Si}-\mathrm{F}$ [9]. Влияние дипольного момента эмитирующей поверхности обнаруживается при увеличении длительности импульсов анодных напряжений: из-за увеличения кинетической энергии электронов в сильных импульсных электрических полях уменьшается длительность их кулоновского взаимодействия с поверхностными диполями. Это способствует ускоренному росту автоэмиссионных токов и более сильному уменьшению порогов автоэмиссии при длительностях импульсов более $30 \mu$ s (рис. 1).
В процессе полевой эмиссии одновременно осуществляется динамическая нейтрализация поверхностных ловушек захвата дрейфующими к поверхности под действием импульсов анодного напряжения электронами. При плазменной обработке кристаллов кремния в среде аргона их заполнение осуществляется достаточно быстро и выражается в практически мгновенном выходе на стационарный режим огибающих амплитуд анодных напряжений уже при длительности импульсов около $10 \mu \mathrm{s}$ (рис. 2). При плазмохимической обработке кристаллов кремния в среде хладона-14 уменьшение огибающих амплитуд анодных импульсов в процессе долговременных испытаний с короткими длительностями импульсов, вероятнее всего, обусловлено увеличением суммарного дипольного момента эмиссионной поверхности. Увеличение происходит в результате адсорбции электронов в поверхностных ловушках захвата и ослабления за счет этого кулоновского взимодействия между зарядами, образующими диполи $\mathrm{Si}-\mathrm{F}$. При длительностях более $30 \mu \mathrm{s}$ увеличиваются собственная энергия и прозрачность потенциальных барьеров для туннелирующих электронов. Благодаря этому в процессе долговременных испытаний амплитуды автоэмиссионных токов увеличиваются, а их выход в стационарный режим происходит практически мгновенно (кривая 2 на рис. 3 ).

\section{Финансирование работы}

Исследование выполнено за счет гранта Российского научного фонда (проект № 16-19-10033).

\section{Список литературы}

[1] Marcus R.B., Ravi T.S., Gmitter T. // Appl. Phys. Lett. 1990. V. 56. N 3. P. 236-238.

[2] Velásquez-García L.F., Guerrera S., Niu Y., Akinwande A.I. // IEEE Trans. Electron Dev. 2011. V. 58. N 6. P. 1783-1791.

[3] Герасименко Н.Н., Пархоменко Ю.Н. Кремний - материал наноэлектроники. М.: Техносфера, 2007. 352 с.

[4] Усnехи наноинженерии: электроника, материалы, структуры / Под ред. Дж. Дэвиса, М. Томсона. М.: Техносфера, $2011.496 \mathrm{c}$.

[5] Ябаров Р.К. Физика СВЧ вакуумно-плазменных нанотехнологий. М.: Физматлит, 2009. 216 с.

[6] Яфаров Р.К., Шаныгин В.Я. // ФТП. 2017. Т. 51. В. 4. C. $558-562$.

[7] Яфаров Р.К. // ФТП. 2019. Т. 53. В. 1. С. 18-25.

[8] Fowler R.H., Nordheim L. // Proc. Roy. Soc. London. A. 1928. V. 119. N 781. P. 173-181.

[9] Яфаров Р.К. // Письма в ЖТФ. 2018. Т. 44. В. 13. С. 68-74.

[10] Оура К., Лифшии В.Г., Саранин А.А., Зотов А.В., Катаяма М. Введение в физику поверхности. М.: Наука, 2006. $490 \mathrm{c}$. 